\title{
Sexual rights but not the right to health? Lesbian and bisexual women in South Africa's National Strategic Plans on HIV and STIs.
}

Felicity Daly $\mathrm{DrPH}^{\mathrm{a}}$, Neil Spicer $\mathrm{PhD}^{\mathrm{b}}$, Samantha Willan $\mathrm{MA}^{\mathrm{c}}$

\section{BACKGROUND}

In the context of widespread homophobia throughout Africa and other regions in the world, South Africa is often seen as a beacon for upholding sexual rights. After South Africa's transition to democracy, lesbian and gay people's rights became more actionable, given the 1996 Constitution's assurance of equality. ${ }^{1}$ Over the past two decades a further set of civil rights, including same-sex marriage, were secured by South Africa's lesbian, gay, bisexual and transgender (LGBT) movement, which is remarkable when compared to the overall negative climate towards sexual minorities elsewhere in Africa. ${ }^{2}$ Additionally South Africa has consciously struggled "against policies and laws that sought to exclude and marginalise people based on race, class, sex, gender, religion, age, disability and sexual orientation"... as part of the ongoing agenda of the International Conference on Population and Development. ${ }^{3}$ Nevertheless, homophobic discrimination persists in South Africa and a 2008 general population survey by South Africa's Human Sciences Research Council (HSRC) showed that $80 \%$ of adults believe that same-sex behaviour is 'always wrong' ${ }^{4}$ LGBT people in South Africa experience discrimination and harassment, particularly in resource-poor settings, in rural areas and townships. ${ }^{5}$ Lesbian and bisexual women or women who have sex with women (WSW) experience marginalisation "both as women and as women who have sex with women living in a patriarchal, heterosexist society". ${ }^{6}$

Social marginalisation is not an uncommon experience for LGBT people, but in South Africa, where the burden of HIV is among the highest worldwide, lesbian and bisexual women experience greater vulnerability to sexual ill-health. Research conducted within South African LGBT communities over the past decade identified HIV prevalence among black WSW at $9 \%$ and found they were at greater risk compared to white WSW. ${ }^{7,8,9,10,11}$ A multi-country study found that WSW in South Africa and other countries in Southern Africa face sexual health risks both within same-sex relationships as well as in heterosexual experiences, including transactional sex with, and forced sex by men. Of WSW

\footnotetext{
a Executive Director, Kaleidoscope Trust, UK

${ }^{b}$ Lecturer, Global Health Policy, London School of Hygiene and Tropical Medicine, UK

${ }^{c}$ Capacity Development Manager, What Works to Prevent Violence against Women and Girls, Medical Research Council, South Africa
} 
living with HIV surveyed , 20\% stated that they believed they were infected during an exclusively same-sex relationship. ${ }^{12,13}$ These findings were unexpected, given that there is little comparable data showing a similar burden of disease elsewhere, and a lack of analysis in both high-income countries and low- and middle-income countries about a range of lesbian and bisexual women's sexual and reproductive health concerns, including risk of acquiring HIV.

There is a common misperception that WSW are not at risk of acquiring STIs, including HIV, ${ }^{1}$ resulting in many WSW having a sense of invincibility to HIV transmission through same-sex relationships ${ }^{14}$, resulting in a "much higher risk for contracting HIV than is generally perceived."15 Although data on incidence and prevalence of HIV and other STIs among WSW in South Africa is limited, there are many self-identified lesbians living with HIV in South Africa who argue that the exclusion of WSW in South Africa's HIV policy, research and prevention initiatives can no longer be justified by assertions that WSW face 'no risk' of HIV transmission in same-sex relationships.

It has been established that gender-based violence (GBV) is a significant driver of women's vulnerability to $\mathrm{HIV}^{16}$, and that Southern Africa has extremely high rates of GBV, with $17 \cdot 4 \%$ of women ever having experienced non-partner sexual violence. ${ }^{17}$ Holland-Muter noted that in South Africa lesbian and bisexual women are targeted for sexual violence explicitly because of their sexuality. This violence, resulting in trauma and increased risk of HIV transmission, has been referred to in the sensationalist media and by certain activists as 'corrective rape', as some perpetrators have stated they intend to 'cure' women of same-sex desire. ${ }^{18}$ Nevertheless, concerns have been raised that South Africa should not regard violence against women, including lesbian and bisexual women, “primarily or solely as a cause of HIV transmission rather than as a serious violation of women's fundamental rights to bodily integrity, personal freedom and sexual agency in itself." ${ }^{19}$

In the South African context, where the right to health is enshrined in the Constitution, health policy development provides unique opportunities to air concerns about even the most marginalised citizens. In 2007, there was a breakthrough in civil society participation in the South African National AIDS Council (SANAC), including the opportunity for lesbians living with HIV to present testimony. The resulting policy content of the HIV and AIDS and STI Strategic Plan for South Africa 2007-2011 included commitments relevant to WSW including: "a customised HIV prevention package for men who have sex with men, lesbians and trans persons; equitable representation of LGBT people in care, treatment and support programmes; and information materials on rights to HIV prevention, treatment and support that responds to the special needs of ... gay and lesbian people." ${ }^{20}$ This was 
remarkable, since lesbian or bisexual women are rarely highlighted for public health interventions or included in national STI or HIV/AIDS policies and particularly not in sub-Saharan Africa, where heterosexual sexual HIV and STI transmission predominates as is often the case in generalised HIV epidemics. Although public health strategies targeting LGBT communities have emerged in the region, they have been focused on preventing HIV among men who have sex with men (MSM) and transgender women, given the high HIV incidence in these populations.

In 2011, South African policy actors developed the National Strategic Plan (NSP) for 2012-2016 within a Ministry of Health mandate to emphasise 'evidence-based' interventions. Normative guidance, particularly from UNAIDS, on the benefits of focusing on key populations vulnerable to HIV, including MSM, to drive down incidence, was influential in shaping policy content. Ultimately, The National Strategic Plan on HIV, STIs and TB 2012- 2016 did not address the HIV and STI risks facing WSW, although it did acknowledge that "discrimination against members of the community with... different sexual orientations (e.g. men who have sex with men and women who have sex with women) ... may result in reluctance to attend health services for fear of discrimination."21

The health policy analysis presented in this article provides some insights into how and why the 2007-2011 NSP initially proposed the implementation of services that would benefit WSW and considers how policy commitments to WSW sexual health evolved over time. It reflects a lack of policy cohesion between sexual rights and access to the right to health for sexual minority women in the context of South African HIV/AIDS and STI policy processes. It also reveals the limitations of GBV policy and programmes to address health concerns emerging from sexual violence experienced by lesbian and bisexual women.

\section{JUSTIFICATION AND METHODS}

The study responds to a call made in 2007 at an HSRC conference for research into the process through which the interests of WSW have been represented in South African HIV/AIDS policy examining the context of LGBT organisations, as well as women's rights, organisations' engagement and how research based advocacy might advance HIV prevention, treatment and care for WSW. ${ }^{22}$ The public health value of the study is grounded in a human rights approach to health, particularly sexual and reproductive health, which considers the causal links between human rights violations and health, and the ways that discrimination on the basis of sexual orientation leads to violations of the right to health ${ }^{23}$ 
This health policy analysis incorporates the factors which Walt and Gilson ${ }^{24}$ (1994) consider to be in play when making health policy: context, content and process with actors - as individuals and as members of groups or organisations - at the centre of a model for health policy analysis. The study utilised qualitative methods to understand the policy process leading to the development of the 2007-2011 NSP and compared it to the 2012-2016 NSP. Data was collected including 25 in-depth, semi-structured interviews conducted in 2013 with key informants involved in HIV policy and LGBT rights in South Africa. The constituencies were represented by: seven representatives of public sector bodies with responsibility for research, health and HIV services, five community-based HIV organizations, four LGBT organisations, three donors, and two multilateral organizations. The sampling approach was purposive and inclusion was based on whether the informant or their organisation: had been engaged in NSP development in 2007 or 2011; was a member of SANAC; provided technical assistance to SANAC; or was involved in the development of evidence on the impact of HIV and STIs among WSW or other populations. An interview topic guide was developed, informed by a theoretical framework, and thematic analysis of data was aided by NVivo 10 research software. This data was triangulated through document analysis of official publications, primarily: the previous (2007-2011) and current (2012-2016) editions of the National Strategic Plans on HIV; official evaluations of the implementation of the 2007-2011 NSP; and reports and submissions prepared for the development of the 2012-2016 NSP.

The theoretical framework was adapted from Shiffman and Smith's ${ }^{25}$ well-known framework of the factors determining political priorities for global initiatives to address maternal mortality, which considered the influence of: actor power, ideas, political contexts, and issue characteristics. The factors were adapted to propose a set of dimensions that play a role in decisions about which health issues are integrated into policy, and applied to a framework on the determinants of political priority for WSW issues to be included in South Africa's NSPs 2007-2011 and 2012-2016.

This article presents findings from the application of the framework categories to explore themes around upholding sexual rights within health policy and addressing gender-based violence as a barrier to sexual and reproductive health for WSW. Actor Power is expressed by the strength and influence of the individuals and organisations, such as LGBT organisations, representing WSW issues in policy development processes in 2007 and 2011. Ideas are the ways in which those representing the concerns of WSW in the realms of sexual health and sexual rights understand and portray them both through an 'internal frame' reflecting policy actors' views on the vulnerability of WSW to HIV and STIs, and an 'external frame' where portrayals of concerns relating to WSW through media 
coverage resonate with the general public, including leaders who control resources. The Political Context captures the political and socio-economic environment in which actors operate. The study found certain moments or 'policy windows' when conditions aligned favourably for WSW issues and presented opportunities for advocates to influence decision makers, and moments when these opportunities were not present. Issue characteristics include epidemiological evidence and other measures demonstrating the nature and scale of problems of poor sexual health and GBV affecting lesbian and bisexual women.

\section{FINDINGS}

\section{Actor Power}

The engagement of policy actors, including from LGBT community-based organisations and other civil society organisations, with the South African National AIDS Council (SANAC) was reviewed over two periods of policy development in 2007 and 2011. Informants were asked which actors were most powerful in getting WSW issues on SANAC's agenda. Many highlighted that actors from LGBT and women's rights organisations from within the SANAC women's sector exerted influence and brought in rights-based arguments about the need to include WSW in SANAC discourse. Their power was in many ways derived from that of the wider social movements coalesced around the response to HIV/AIDS which were increasingly holding Government to account, and enabled many civil society organisations to have a voice. It was noted that civil society movements such as the Treatment Action Campaign had been instrumental in changing the South African Government's response to HIV/AIDS. An informant from academia argued that the 2007 process was influenced by 'networks of activist organisations within South Africa and...across borders globally.'

Many informants reflected that the National Strategic Plan policy consultation in 2007 was highly participatory compared with earlier and later policy development processes. An informant from an HIV/AIDS organisation recalled 'a lengthy participatory process...open, inclusive spaces...there you can strongly raise particular issues.' An informant from the public sector remembered the process as 'very long and painstaking but it had a lot of participation and a lot of energy.' Several informants remarked that there were a greater number of organisations who were able to engage in advocacy and input into the consultation in 2007 compared to later on and the findings showed that the SANAC women's sector included members who advocated for lesbians affected by HIV. Between 2007 and 2011 several developments negatively impacted the ability of actors concerned with WSW to influence HIV and STI policy making. The balance of power within SANAC seemed to shift to development partners, including government donors and technical agencies, particularly UNAIDS, and privileged their input over that of community-based organisations. Actors focusing on WSW 
seemed to be easily overlooked in the later process as organisations with greater power and resources rose to prominence in policy formulation. An informant from an LGBT organisation reflected that in 2011 'we got side lined.'

The study found that between 2007 and 2011 civil society spaces, including the SANAC women's sector, were weaker and that LGBT organisations in particular struggled to engage in policy discourse to the same degree that they had in 2007. Policy actors in the Department of Health became increasingly concerned with demonstrating technical capacity and by 2011 they were focusing on 'game changers' in the HIV response. An informant from an HIV/AIDS organisation offered that 'organisations that have much more clout than the LGBTI community have suffered...how much more so an organisation that didn't have a very strong voice?' Findings showed that actor power among advocates for WSW diminished considerably over time due to a variety of factors: economic constraints due to changes in external resources; growing social conservatism including among women's groups; and a lack of cohesion among LGBT organisations trying to capture the opportunities afforded them by prioritising the issues where there was the strongest epidemiologic evidence, particularly HIV vulnerability among MSM.

SANAC'S LGBTI sector was established between the two processes and was engaged in the development of the 2012-2016 NSP. Many informants reflected that the sector quickly became almost wholly concerned with MSM policy and programmes, a focus most found was justified by the epidemiological data on MSM and HIV in South Africa. An informant from civil society stressed that there was no policy community cohesion among the various constituencies meant to be represented by the LGBTI sector: 'there isn't a united voice...in the context of HIV exposure, transmission and related rights abuses, WSW have extreme(ly) different realities and risk(s) than MSM.'

Ideas:

Policy actors demonstrated little agreement on the definition of, causes of, and solutions to WSW vulnerability to HIV and other STIs over both time periods. In 2007 policy actors promoting WSW sexual health first engaged in NSP development by delivering personal testimony of the lived realities of lesbian and bisexual women in South Africa, where the Constitutional commitment to non-discrimination on the basis of sexual orientation was not being realised, in a context of epidemic levels of HIV and GBV. An informant from the public sector argued that although the country has 'all of these wonderful, progressive constitutional protections...there hasn't been any tangible difference to the real lives of women.' An informant from a civil society organisation shared their perception 
that between 2007 and 2011 the space for raising emerging evidence regarding WSW within the South African National AIDS Council 'got smaller and smaller' and that the response to available data was usually to compare the statistical significance of WSW living with HIV to populations with a higher burden of HIV and as a result 'the discussion (around WSW) was pretty much put to an end.'

Several informants noted that while homosexuality was still criminalised and new legislation was being proposed elsewhere in Africa, South Africa is still considered progressive on LGBT rights. However, an informant from an LGBT organisation shared 'we live under this belief that what we can be free...yet there is a...backlash.' Another LGBT organisation informant reflected on the increase of conservatism in South African civil society, among faith based communities in particular, which had a bearing on what is possible to assert in heath policy processes, given that 'discrimination towards sexual minorities is widespread... within policy makers and that definitely has implications on...how policies are drafted and what gets implemented, what gets prioritised, what gets funded.' An informant from a bilateral donor argued that although WSW sexual health needs had originally being cited within the 2007-2011 NSP 'South Africa as a whole...is not willing...to acknowledge there (are) WSW... and therefore address (them).'

In both the 2007 and 2011 NSP development processes, certain policy actors tried to utilise ideas about GBV response as a way to integrate concerns around WSW sexual health. The findings note that while policies to combat GBV exist in South Africa, they are not implemented and overall this entrenched problem had suffered from a poor government response. Moreover the public sector response to GBV had failed to confront sexual violence motivated by homophobia, including rape of lesbian, bisexual and gender non-conforming women because of their sexual orientation and/or gender identity. When considering public representations of health concerns facing lesbian and bisexual women, it was apparent that there was often a media-driven outcry around 'corrective rape'. Nevertheless, sensationalist media coverage did not reveal linkages between GBV and HIV risks nor address the marginalisation of lesbian and bisexual victims of violence in the health or criminal justice systems. Informants explained that greater visibility following media coverage did not lead to sustainable policy actions or result in any statements by political leaders objecting to sexual violence experienced by lesbian and bisexual women.

\section{Political Context}

Many informants reflected that 2007 marked the time when the South Africa Government began to move on from their previously disastrous position on HIV/AIDS, including its refusal to provide 
antiretroviral treatment to South Africans living with HIV through the public sector. An informant from the public sector recalled 'lots of battles... with our...actual Government.' Thus, there were what Kingdon ${ }^{26}$ referred to as 'policy windows'; political moments when conditions align favourably, presenting advocates with opportunities to influence decision makers. These windows were open in 2007, wherein more marginal voices could be raised within policy development, allowing for significant civil society participation. This openness was less apparent in 2011 as a new Minister of Health placed greater emphasis on 'evidence-based' health policy and managed the NSP policy process in order to avoid producing a 'laundry list' that could not be implemented. The scope of the policy was further constrained by diminished resources due to: the global recession; the withdrawal of some bilateral donors; loss of private foundation resources for the LGBT sector; and limits of funding available for women's rights organisations. Social conservatives were more emboldened by 2011, acting in concert with President Zuma's problematic attitudes towards women and sexual minorities. As an informant from a faith-based organisation noted, there were many prominent voices that 'do not support LGBTI rights in any way, shape or form.' They noted that within this conservative context, WSW are not 'even seen' and have few advocates as 'there are very few religious leaders...that will take on that whole culture, gender, legal nexus.'

\section{Issue characteristics}

When analysing the factor of issue characteristics, the study found that there were few objective health metrics that could be utilised to help decision makers prioritise the sexual health concerns of WSW. There was limited data on incidence and prevalence of HIV and other STIs among WSW. Given that very few public health interventions specific to WSW had been attempted, there was little information on effectiveness of or barriers to implemented activities. Personal testimony from lesbians living with HIV was considered 'anecdotal' evidence, which is seldom given much weight in policy discourse. Testimonies of lesbian and bisexual women who had personally experienced sexual violence was also aired and '(made) the broader connections around violence and health...[and] the challenges of living in a deep seeded patriarchy.' An informant from an LGBT community organisation reflected that the point of such testimony was 'not necessarily only about (HIV and STI) prevalence but...about human rights.' Challenges lesbian and bisexual women have faced following sexual violence 'secondary victimisation' was also expressed as: limits of reporting in the criminal justice system; lack of conviction of perpetrators; failures of care in the health system, such as lack of provision of post exposure prophylaxis (PEP) to prevent HIV transmission; and little recourse to psycho/social care. 
In 2011, studies on WSW conducted since $2007^{27,28,29}$ were either not widely disseminated or not considered strong enough. Many informants spoke to this being a critical factor behind a change in policy discourse as policy actors were mandated to develop an 'evidence-based' plan. Lack of resources to disseminate findings or undertake further research was cited as a key reason for poor understanding of these health concerns. The findings suggest that in 2011 discussions about the HIV risks of WSW through sex with men, including for transactional purposes or as a result of sexual violence, were regarded as valid concerns. As a principle underpinning, the 2012-2016 NSP articulated that interventions should be "based upon evidence...[in] instances in which there is a lack of evidence, a clear motivation should be given...supporting the prioritisation of the intervention, e.g. rights-based arguments". ${ }^{30}$ However, interviews and document review revealed that rightsbased arguments, which had been lodged on behalf of WSW in the consultation process, were not secured in the final policy document.

\section{DISCUSSION}

The study revealed that the inclusion of WSW within several objectives of the 2007-2011 NSP was largely based on personal testimony delivered by lesbians living with HIV. This anecdotal evidence might have been overlooked if not for the strong voices of these actors and the overall success of activism on the right to health, particularly by the Treatment Action Campaign. Perhaps a more strategic approach to advocacy around WSW sexual health within SANAC in 2007 could have been to call for a well-resourced research agenda for more data on HIV and STI prevalence and incidence among WSW in various communities/locations in South Africa. By 2011, several WSW sexual health studies had been undertaken in the country, but few policy actors seemed informed about the findings and those that were aware of them did not consider them sufficiently strong enough to make the case for inclusion of prevention efforts for WSW in the 2012-2016 NSP. This was, in part, due to inherent problems with conducting research among marginalised populations with small sample sizes where the resulting data is often insufficiently powered to be considered statistically significant. ${ }^{31}$

The limits of epidemiological data to support concerns about WSW seems to have been a key factor in relegating these concerns to the margins of policy discourse in 2011 in a context where the Ministry of Health insisted on an 'evidence-based' plan. The findings also suggest that heteronormative views of women's sexuality may have politicised discussions of HIV and STIs among lesbian and bisexual women, which has also been marginal within HIV research. This reflects a general lack of attention to health disparities among lesbian and bisexual women. ${ }^{32}$ Nevertheless, in 
the changing context of a technocratic policy process, less concerned with ensuring broad commitments to the right to health than with posing a solid case for implementing evidence-based programming, it may have been inevitable that issues facing sexual minority women would have difficulty being expressed.

While the severity of health concerns can be demonstrated through metrics, there are also many social and political aspects which often come into play in policy discourse around sexual health and sexual behaviour. Factors, such as social marginalisation of women, especially gender nonconforming women, and those with non-heteronormative sexual behaviour, tend to complicate health policy discourse. There is a lack of policy cohesion between the South African Constitution's aspiration to end discrimination on the basis of sexual orientation and promote the right to health that is apparent in the poor sexual health and the experience of sexual violence among lesbian and bisexual women. This impedes their access to the public health and criminal justice systems wherein they continue to face stigma and discrimination. ${ }^{33}$

Given that policy actors interviewed seem to understand that sexual violence experienced by lesbian and bisexual women, interventions to address GBV or Intimate Partner Violence (IPV) must be utilised to address WSW concerns. The 2012-2016 NSP notes that women's vulnerability to HIV is especially high among "survivors of physical and/or intimate partner violence", ${ }^{34}$ supported by a study on power, inequality and violence within heterosexual relationships. ${ }^{35} \mathrm{Clearly}$, 'corrective rape', a homophobic hate crime targeting WSW, is not IPV. Moreover, IPV is often framed in a heteronormative context which may not capture forced sex within women's same sex partnerships, an issue that was uncovered in a multi-country study on WSW affected by HIV. ${ }^{36}$ While GBV and/or IPV policy may intend to capture sexual violence perpetrated on the basis of non-heteronormative sexuality and gender non-conformity, it is necessary to consider how violence experienced by lesbian and bisexual women differs from other forms of sexual violence so that responses can be better targeted to meet these women's needs. Sensitisation of health providers and the police and judiciary is required in order to address the specific service access barriers faced by lesbian and bisexual women subject to homophobic sexual violence. Otherwise there will be limited scope for GBV/IPV programming to benefit WSW.

Although there has been much sensationalism in South Africa's tabloid media around 'corrective rape' and murders of lesbian and bisexual women, other public discourse has been limited. In particular the linkages between this form of sexual violence and arising health threats for lesbian 
and bisexual victims, including HIV transmission, has been overlooked. Conversely, some advocates for lesbian and bisexual women are wary of equating the lived reality of lesbians and bisexual women solely with the threat or perpetration of sexual violence. Instead, they would like national health policy to support sexual health programming that promotes holistic considerations of healthy relationships between women which asserts their sexual rights and their well-being, including addressing safer sex within same-sex relationships and with other partners.

\section{CONCLUSION}

Our findings indicate that receptivity to rights-based arguments around lesbian and bisexual women's vulnerabilities to HIV and other STIs declined between 2007 and 2011, and these changes in policy discourse resulted in reduced attention to sexual health risks of WSW and their ability to claim the right to health. Interviews with a range of academics, civil society, donors, government officials and service providers revealed varying levels of understanding of the structural and epidemiological drivers of sexual ill-health among WSW. Overall, it was stressed that decision making for the NSP has an imperative to address a generalised HIV epidemic and the needs of populations for which high vulnerability to HIV has been established by strong evidence. While there are policy actors who hold a better understanding of WSW vulnerability to HIV and other STIs, taking action remains a low priority in policy and implementation due to a variety of factors discussed herein.

While HIV policy increasingly asserts the importance of promoting sexual rights for MSM and sex workers in particular, it remains unexplored for lesbian and bisexual women as well as other sexual and gender minorities. Historically, solidarity among gay men and lesbians has been essential to enshrine sexual rights in South African law, however, the disparate contexts of MSM and WSW sexual health in terms of both epidemiology and structural drivers of vulnerability may mean that their needs would be better addressed through different policy approaches that identify shortfalls in meeting the diverse health needs of LGBTI populations.

In the next phase of NSP development in 2016, advocates for lesbian and bisexual women will need to reiterate South Africa's obligations in line with the constitutional right to health and nondiscrimination on the basis of sexual orientation. They should continue to ensure that women in all their diversity are meaningfully engaged in policy consultation. Policy actors must also review GBV initiatives to ensure that implementation addresses lesbian and bisexual women's experiences of 
sexual violence, and utilise attention on GBV as a structural driver of HIV as an entry point to raise issues relevant to WSW.

Various civil society actors, including from within SANAC's LGBTI and Women's Sectors, need additional capacity to marshal the existing quantitative and qualitative evidence of the burden of STIs including HIV among WSW. Advocates could also urge for investment in additional research intended to demonstrate the epidemiological and structural drivers of HIV and STIs in women's same-sex relationships. These would include gender inequality, discrimination on the basis of sexual orientation and intersectional dynamics of social marginalisation. Meeting the evidence threshold is only one part of the challenge of policy engagement. ${ }^{37}$ More importantly, getting agreement on whether and how to include the needs of lesbian and bisexual women in HIV and STI policy must engage a wider constituency of academics, civil society, health workers and policy makers, all of whom have various demands that will shape the content of future National Strategic Plans.

Now that evidence of WSW vulnerability to STIs including HIV has emerged elsewhere in Southern Africa, ${ }^{38}$ LGBT organisations and others should reflect on the success and limitations of the South African experience. It is hoped that these insights will inform advocates on behalf of lesbian and bisexual women's sexual health to engage more effectively with policy actors within SANAC and in other government bodies. As representatives of the first African nation to enshrine these rights in law, South African policy actors have a responsibility to uphold the sexual rights and the right to health of lesbian and bisexual women.

\section{References}

${ }^{1}$ Reid, G. \& Walker, L. 2005. Sex and secrecy: a focus on African sexualities. Cult Health Sex, 7, 185-94.

2 Johnson, C. A. 2007. Off the map. How HIV/AIDS programming is failing same-sex practicing people in Africa.

${ }^{3}$ Statement by Minister Of Social Development Ms. B.O. Dlamini , Republic Of South Africa to the 29th Special Session of the UN General Assembly On The Follow-Up To The Programme Of Action of the International Conference on Population And Development (ICPD) New York, 22 September 2014.

${ }^{4}$ Roberts, B. \& Reddy, V. 2008. Pride and prejudice: Public attitudes toward homosexuality. HSRC review, 6, 911.

${ }^{5}$ Reid G, Dirsuweit T. Understanding systemic violence: Homophobic attacks in Johannesburg and its surrounds. Urban Forum. 2002;13:99-126

${ }^{6}$ Tallis, V. 2012. Feminisms, HIV and AIDS: subverting power, reducing vulnerability, Palgrave Macmillan. p 11.

${ }^{7}$ Wells, H. \& Polders, L. 2004a. HIV and Sexually Transmitted Infections (STIs) among Gay and Lesbian people in Gauteng: Prevalence and Testing Practices. Pretoria, Gauteng, South Africa: OUT LGBT Wellbeing.

${ }^{8}$ Wells, H. \& Polders, L. 2004b. Levels of Empowerment among Lesbian, Gay, Bisexual and Transgender (LGBT) People in Gauteng, South Africa. Pretoria, Gauteng, South Africa OUT LGBT Wellbeing.

${ }^{9}$ Wells, H. 2006. Levels of Empowerment among Lesbian, Gay, Bisexual and Transgender (LGBT) People in KwaZulu-Natal, South Africa Pretoria Out LGBT Wellbeing. 
${ }^{10}$ Rich, E. 2006. Levels of Empowerment among LGBT People in the Western Cape, South Africa Cape Town Triangle Project and University of South Africa Centre for Applied Psychology.

${ }^{11}$ Cloete, A., Sanger, N. \& Simbayi, L. C. 2011. Are HIV positive women who have sex with women (WSW) an unrecognized and neglected HIV risk group in South Africa? Journal of AIDS and HIV Research, 3, 1-5.

12 Sandfort, T. G., Baumann, L. R., Matebeni, Z., Reddy, V. \& Southey-Swartz, I. 2013. Forced sexual experiences as risk factor for self-reported HIV infection among southern African lesbian and bisexual women. PLoS One, 8, e53552.

${ }^{13}$ Matebeni, Z., Reddy, V., Sandfort, T. \& Southey-Swartz, I. 2013. "I thought we are safe": Southern African lesbians' experiences of living with HIV. Cult Health Sex, 15 Suppl, 34-47.

${ }^{14}$ Dolan, K. A. \& Davis, P. W. 2003. Nuances and shifts in lesbian women's constructions of STI and HIV vulnerability. Soc Sci Med, 57, 25-38.

${ }^{15}$ Fishman, S. J. \& Anderson, E. H. 2003. Perception of HIV and safer sexual behaviors among lesbians. J Assoc Nurses AIDS Care, 14, 48-55. p 53

${ }^{16}$ Stockman, J. K., Lucea, M. B. \& Campbell, J. C. 2013. Forced sexual initiation, sexual intimate partner violence and HIV risk in women: a global review of the literature. AIDS Behav, 17, 832-47.

${ }^{17}$ Abrahams, N., Devries, K., Watts, C., Pallitto, C., Petzold, M., Shamu, S. \& Garcia-Moreno, C. 2014. Worldwide prevalence of non-partner sexual violence: a systematic review. Lancet, 383, 1648-54.

${ }^{18}$ Holland-Muter, S. 2012 . Outside the Safety Zone: An Agenda for Research on Gender-Based Violence Targeting Lesbian and Bisexual Women in South Africa, Braamfontein, South Africa, Ma Thokos Books.

${ }^{19}$ Nath, D. 2012 "We Were Never Meant to Survive": Violence in the Lives of HIV Positive Women in South Africa. The One in Nine Campaign.

${ }^{20}$ Republic Of South Africa 2007. The HIV \&AIDS and STI Strategic Plan for South Africa 2007-2011.

${ }^{21}$ Republic of South Africa. 2011: 39. National Strategic Plan on HIV, STIs and TB 2012-2016.

${ }^{22}$ Sandfort, T., Reddy, V. \& Rispel, L. Taking research and prevention forward. In: Reddy, V., Sandfort, T. \&

Rispel, L., eds. From Social Silence to Social Science. Same sex sexuality, HIV and AIDS and Gender in South Africa, 2007 Pretoria, South Africa HSRC Press, 228-241.

${ }^{23}$ Miller, A. 2000. Sexual But Not Reproductive: Exploring the Junction and Disjunction of Sexual and Reproductive Rights. Health Hum Rights, 4, 68-109.

${ }^{24}$ Walt, G. \& Gilson, L. 1994. Reforming the health sector in developing countries: the central role of policy analysis. Health Policy Plan, 9, 353-70.

${ }^{25}$ Shiffman, J. \& Smith, S. 2007. Generation of political priority for global health initiatives: a framework and case study of maternal mortality. Lancet, 370, 1370-9.

${ }^{26}$ Kingdon, J. 2003. Agendas, alternatives, and public policies. Longman classics in political science.

${ }^{27}$ Cloete, A., Sanger, N. \& Simbayi, L. C. 2011. Are HIV positive women who have sex with women (WSW) an unrecognized and neglected HIV risk group in South Africa? Journal of AIDS and HIV Research, 3, 1-5.

${ }^{28}$ Sandfort, T. G., Baumann, L. R., Matebeni, Z., Reddy, V. \& Southey-Swartz, I. 2013. Forced sexual experiences as risk factor for self-reported HIV infection among southern African lesbian and bisexual women. PLoS One, 8, e53552.

${ }^{29}$ Matebeni, Z., Reddy, V., Sandfort, T. \& Southey-Swartz, I. 2013. "I thought we are safe": Southern African lesbians' experiences of living with HIV. Cult Health Sex, 15 Suppl, 34-47.

${ }^{30}$ Republic of South Africa 2011. National Strategic Plan on HIV, STIs and TB 2012-2016 Pretoria, Gauteng, South Africa. P 21.

${ }^{31}$ Malterud, K., Bjorkman, M., Flatval, M., Ohnstad, A., Thesen, J. \& Rortveit, G. 2009. Epidemiological research on marginalized groups implies major validity challenges; lesbian health as an example. J Clin Epidemiol, 62, 703-10.

${ }^{32}$ Richardson, D. 2000. The social construction of immunity: HIV risk perception and prevention among lesbians and bisexual women. Culture, Health \& Sexuality, 2, 33-49.

${ }^{33}$ Smith R. 2015. Healthcare experiences of lesbian and bisexual women in Cape Town, South Africa, Culture, Health \& Sexuality, 17:2, 180-193.

${ }^{34}$ Republic Of South Africa 2011. National Strategic Plan on HIV, STIs and TB 2012-2016. Pretoria, Gauteng, South Africa. P 25.

35 Jewkes, R. K., Dunkle, K., Nduna, M. \& Shai, N. 2010. Intimate partner violence, relationship power inequity, and incidence of HIV infection in young women in South Africa: a cohort study. Lancet, 376, 41-8.

${ }^{36}$ Sandfort, T. G., Baumann, L. R., Matebeni, Z., Reddy, V. \& Southey-SWARTZ, I. 2013. Forced sexual experiences as risk factor for self-reported HIV infection among southern African lesbian and bisexual women. PLoS One, 8, e53552. 
37 Klugman, B. 'Effective social justice advocacy: a theory-of-change framework for assessing progress', Reproductive Health Matters, 19(38) 2011:146-162

38 Ibid, Poteat, T., Logie, C., Adams, D., Lebona, J., Letsie, P., Beyrer, C. \& Baral, S. 2014. Sexual Practices, Identities And Health Among Women Who Have Sex With Women In Lesotho - A Mixed-Methods Study. Cult Health Sex, 16, 120-35. 